\title{
The Effect of Oxygen Partial Pressure during Heat Treatment on the Microstructure of Dip-coated Bi-2212/Ag and Ag Alloy Tapes
}

\author{
Hiroki Fujii, Hiroaki Kumakura, Hitoshi Kitaguchi and Kazumasa Togano \\ National Research Institute for Metals, Sengen 1-2-1, Tsukuba 305, JAPAN \\ Wei Zhang, Yi Feng and Eric E. Hellstrom \\ Applied Superconductivity Center, University of Wisconsin-Madison, WI 53706
}

\begin{abstract}
The evolution of the microstructure during heat treatment was investigated for dip-coated $\mathrm{Bi}_{2} \mathrm{Sr}_{2} \mathrm{CaCu}_{2} \mathrm{O}_{y}(\mathrm{Bi}$ 2212)/ $\mathrm{Ag}$ and $\mathrm{Ag}$ alloy tapes as a function of temperature and oxygen partial pressure $\left(P_{\mathrm{O}_{2}}=\mathbf{0 . 0 1}, 0.21\right.$ and $\left.1 \mathrm{~atm}\right)$ using quenched and fully-processed tapes. The microstructures were essentially the same for Bi-2212 on pure Ag and on the Ag alloy. Although the melting temperature of $\mathrm{Bi}$-2212 increased with increasing $P_{\mathrm{O} 2}$, the solidification temperature $\left(T_{\mathrm{sol}}\right)$ of $\mathrm{Bi}-2212$ for $P_{\mathrm{O} 2}=0.21$ atm was higher than that for $P_{\mathrm{O}_{2}}=1 \mathrm{~atm}$. The volume fraction and grain alignment of $\mathrm{Bi}-2212$ processed in $\boldsymbol{P}_{\mathrm{O} 2}=\mathbf{0 . 0 1} \mathrm{atm}$ was smaller than in tapes processed in 0.21 and 1 atm, which were quite similar. HR-TEM studies on grain boundaries and AC susceptibility measurements suggest that the higher critical current density $\left(J_{c}\right)$ for tapes processed in $P_{\mathrm{O}_{2}}=1 \mathrm{~atm}$ than that for $0.21 \mathrm{~atm}$ is due to improved coupling of the grains.
\end{abstract}

\section{INTRODUCTION}

$\mathrm{Bi}-2212 / \mathrm{Ag}$ composite tape is one of the promising materials for application in wires and coils at low temperature due to its high critical current density $\left(J_{\mathrm{c}}\right)[1],[2]$. It was reported that the $J_{\mathrm{c}}$ was influenced by oxygen partial pressure $\left(P_{\mathrm{O} 2}\right)$ during processing [3]-[5]. We reported that the $J_{\mathrm{C}}$ values of $\mathrm{Bi}$ $2212 / \mathrm{Ag}$ tapes were $0.5,1.2$ and $2 \times 10^{5} \mathrm{~A} / \mathrm{cm}^{2}(4.2 \mathrm{~K}, 10 \mathrm{~T})$ when processed in $P_{\mathrm{O} 2}=0.01,0.21$ and $1 \mathrm{~atm}$, respectively [3]. From practical applications, a Ag alloy with higher strength than pure $\mathrm{Ag}$ is preferred to withstand the large Lorenz force in high magnetic fields [6],[7]. The yield strength of the Ag alloy tapes used in this study was twice of that of pure Ag [8]. In this study, we investigated the evolution of the microstructure during heat treatment for dip-coated $\mathrm{Bi}-2212$ on pure $\mathrm{Ag}$ and $\mathrm{Ag}$ alloy tapes as a function of temperature and $P_{\mathrm{O} 2}$ using quenched and fully-processed tapes. The relationship between the microstructure and $J_{\mathrm{c}}$ of the $\mathrm{Bi}-2212 / \mathrm{Ag}$ alloy tapes processed in various $P_{\mathrm{O} 2}$ is discussed in comparison with the results of $\mathrm{Bi}$ 2212/Ag tapes by doctor-blade method [3].

\section{EXPERIMENTAL}

Bi-2212, of overall composition $\mathrm{Bi}_{2} \mathrm{Sr}_{2} \mathrm{Ca}_{0.96} \mathrm{Cu}_{2} \mathrm{O}_{y}$ was dip-

Manuscript received August 27, 1996. coated on $\mathrm{Ag}$ and $\mathrm{Ag}$ alloy tape. The alloy composition was $\mathrm{Ag}-0.067 \mathrm{at} \% \mathrm{Mg}-0.019 \mathrm{at} \% \mathrm{Zr}$. The tapes were heated up to the maximum processing temperature, $T_{\max }$, which varied with the processing $P_{\mathrm{O} 2}$. The $T_{\max }$ that gave the highest $J_{\mathrm{c}}$ was 840,880 and $885^{\circ} \mathrm{C}$ for $P_{\mathrm{O} 2}=0.01,0.21$ and $1 \mathrm{~atm}$, respectively [3]. The tapes were held at $T_{\max }$ for 5 minutes, then cooled down at 10 $\mathrm{K} / \mathrm{hr}$ for $5 \mathrm{hrs}$, and finally furnace-cooled to room temperature. For the microstructural analysis, tapes were quenched into an oil bath every $5{ }^{\circ} \mathrm{C}$ during cooling from $T_{\max }$. The surface and polished cross sections of the tapes were examined with a scanning electron microscope (SEM) using backscattering electron image. The phases were identified using energy dispersive X-ray spectroscopy (EDX) on the SEM. X-ray diffraction (XRD) was performed on the tape surface and rocking curves were measured to investigate grain alignment. High-resolution electron microscopy (HR-TEM) images of Bi2212 grain boundaries were recorded using a JEOL JEM4000EX. HR-TEM specimens were prepared by grinding, dimpling and finally ion milling with a liquid nitrogen cooled stage. AC susceptibility measurements were performed in magnetic fields ranging from 0.02 to $2 \mathrm{Oe}$.

\section{RESULTS AND DISCUSSION}

Fig. 1 shows the typical microstructure of tapes with Ag alloy substrates quenched from $T_{\max }$ in the different $P_{\mathrm{O} 2} \mathrm{~s}$. At $T_{\max }$, the melt contains liquid, and Bi-free and Cu-free nonsuperconducting phases. The identity of the nonsuperconducting phases varied with $P_{\mathrm{O} 2}$. Table I summarizes the phases found in tapes on Ag and the Ag alloy at different temperatures while processing in the different $P_{\mathrm{O} 2} \mathrm{~S}$. There is no difference in the phase assemblage or the composition of the nonsuperconducting crystalline phases on pure $\mathrm{Ag}$ and the $\mathrm{Ag}$ alloy at each temperature for the different $P_{\mathrm{O} 2} \mathrm{~s}$. Although the melting temperature of $\mathrm{Bi}-2212$ increased with increasing $P_{\mathrm{O} 2}$, the solidification temperature $\left(T_{\text {sol }}\right)$ of $\mathrm{Bi}$ 2212 for $P_{\mathrm{O} 2}=0.21 \mathrm{~atm}$ was higher than that for $P_{\mathrm{O} 2}=1 \mathrm{~atm}$ on both pure $\mathrm{Ag}$ and the $\mathrm{Ag}$ alloy. Similar results were reported for Ag-sheathed Bi-2212 conductors [4].

Fig. 2 shows the typical microstructure of the tapes with $\mathrm{Ag}$ alloy substrates fully processed in the different $P_{\mathrm{O} 2} \mathrm{~S}$. Comparing Figs. 1 and 2, we see that most of the liquid and nonsuperconducting crystalline phases were consumed as the $\mathrm{Bi}-2212$ formed during cooling. The fully processed tapes were 

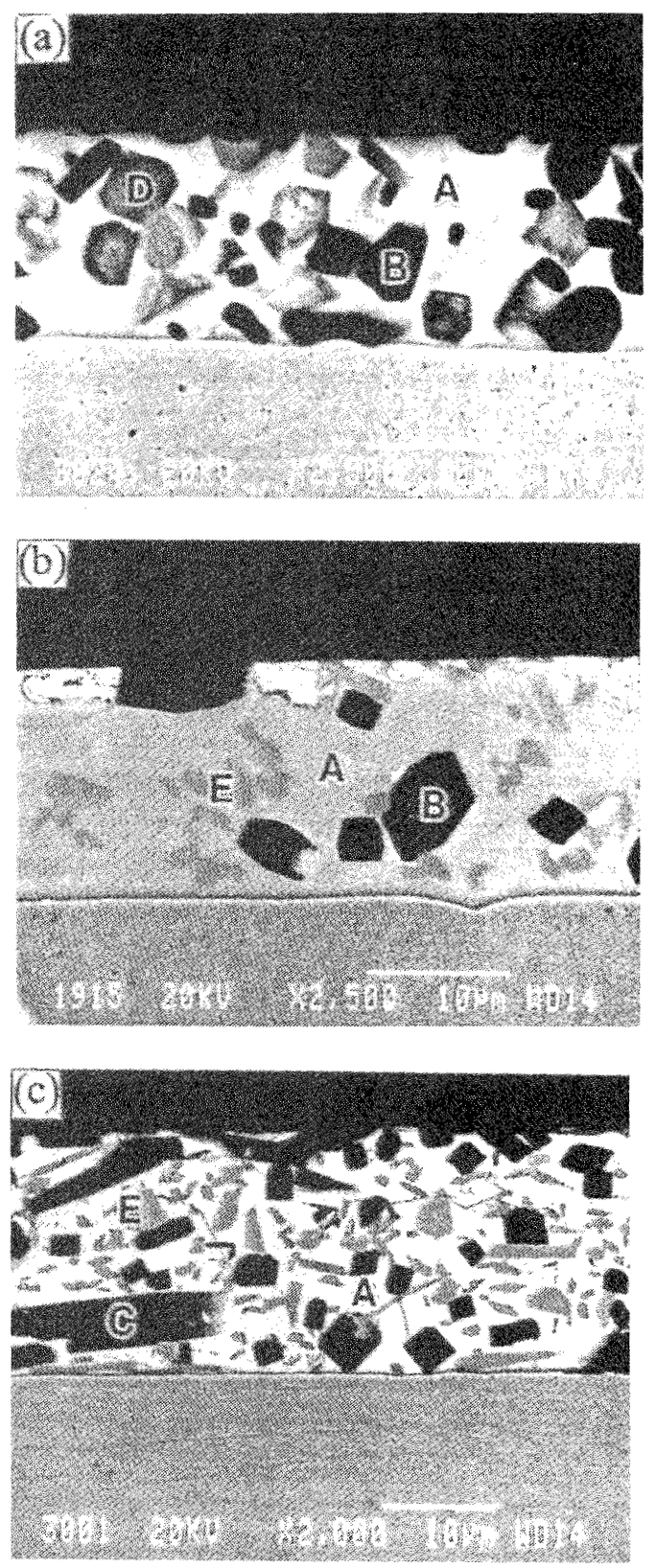

Fig. 1. Backscattered electron images of polished cross sections of $\mathrm{Bi}-2212 / \mathrm{Ag}$ alloy tapes quenched from $T_{\max }$, (a) $840^{\circ} \mathrm{C}$ in $P_{\mathrm{O} z}=0.01 \mathrm{~atm}$, (b) $880^{\circ} \mathrm{C}$ in $P_{\mathrm{O} 2}=0.21 \mathrm{~atm}$, and (c) $885{ }^{\circ} \mathrm{C}$ in $P_{\mathrm{O} 2}=1 \mathrm{~atm}$. A $=$ liquid, $\mathrm{B}=(\mathrm{Sr}, \mathrm{Ca}) \mathrm{CuO} \mathrm{O}_{\gamma}$, $\mathrm{C}=(\mathrm{Sr}, \mathrm{Ca})_{14} \mathrm{Cu}_{24} \mathrm{O}_{y}, \mathrm{D}=\mathrm{Bi}_{2}(\mathrm{Sr}, \mathrm{Ca})_{3} \mathrm{O}_{y}, \mathrm{E}=\mathrm{Bi} i_{2}(\mathrm{Sr}, \mathrm{Ca})_{4} \mathrm{O}_{\psi}$.

free of remnant grains of the $\mathrm{Bi}$-free phase except for the tape processed in $P_{\mathrm{O}_{2}}=0.01 \mathrm{~atm}$ where both $\mathrm{Bi}$-free and $\mathrm{Cu}$-free phases were observed.

The volume fraction of nonsuperconducting crystalline phases and pores was greatest in the melt for tape processed in $P_{\mathrm{O}_{2}}=0.01 \mathrm{~atm}$ (Fig. 1) and was smaller in tapes processed in $P_{\mathrm{O} 2}=0.21$ and $1 \mathrm{~atm}$. The tape processed in $P_{\mathrm{O} 2}=1 \mathrm{~atm}$ had a rougher surface than tape processed in $P_{\mathrm{O} 2}=0.21 \mathrm{~atm}$ (Fig. 2).
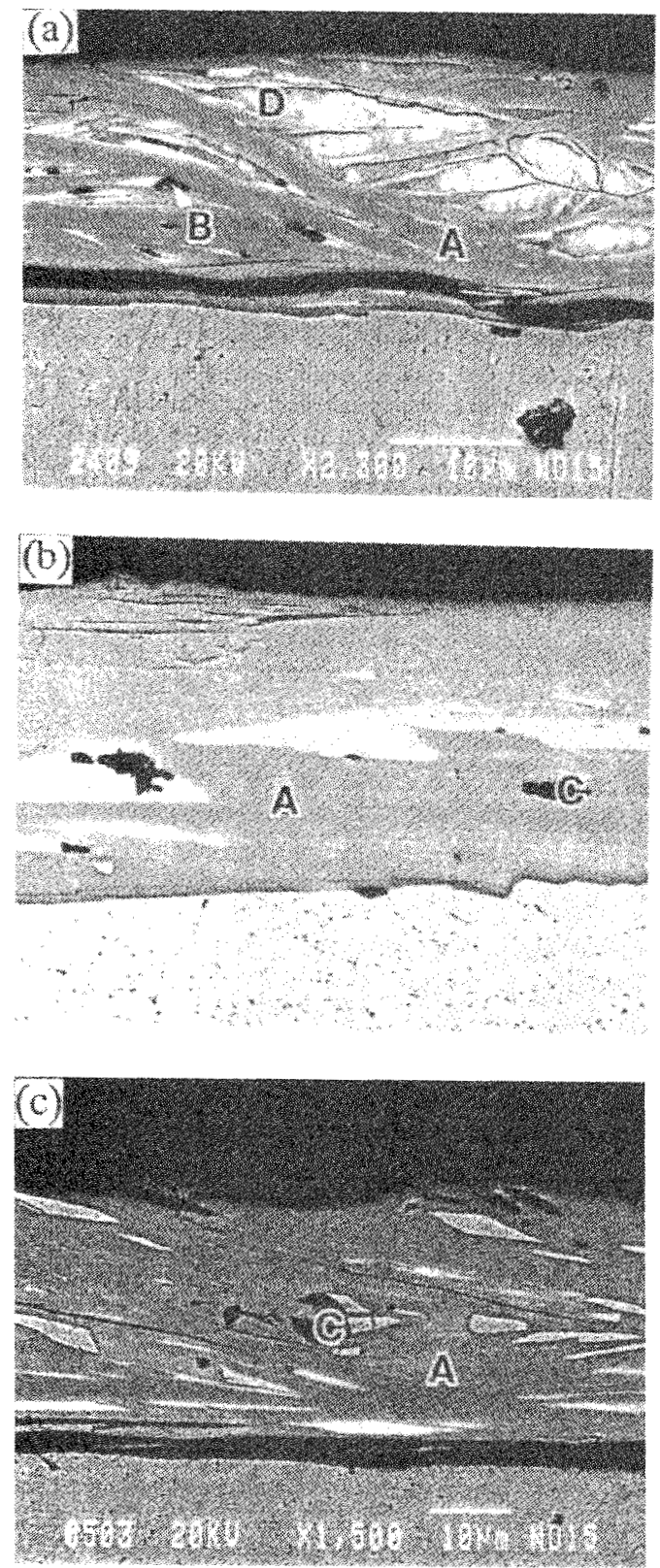

Fig. 2. Backscattered electron images of polished cross sections of $\mathrm{Bi}-2212 / \mathrm{Ag}$ alloy tapes fully processed in $P_{\mathrm{O} 2}=$ (a) 0.01 , (b) 0.21 , and (c) 1 atm. $\mathrm{A}=\mathrm{Bi}-2212$, $\mathrm{B}=(\mathrm{Sr}, \mathrm{Ca}) \mathrm{CuO}_{y}, \mathrm{C}=(\mathrm{Sr}, \mathrm{Ca})_{14} \mathrm{Cu}_{24} \mathrm{O}_{y}, \mathrm{D}=\mathrm{Bi}{ }_{2}(\mathrm{Sr}, \mathrm{Ca})_{3} \mathrm{O}_{y}$.

$X$-ray rocking curves of 0010 reflection in Fig. 3 showed that the full width at half maximum (FWHM) was $\theta=10.0,7.5$ and 9.5 degree for tapes fully processed in $P_{\mathrm{O} 2}=0.01,0.21$ and 1 atm. Although the different samples processed in the same $P_{\mathrm{O}_{2}}$ gave different FWHM values, it was reproducible that the tape processed in $P_{\mathrm{O}_{2}}=0.21 \mathrm{~atm}$ had better $\mathrm{Bi}-2212$ alignment than the other atmospheres. $J_{\mathrm{c}}$ for $P_{\mathrm{O} 2}=0.01,0.21$ and $1 \mathrm{~atm}$ are 0.5 , 1.2 and $2 \times 10^{5} \mathrm{~N} / \mathrm{cm}^{2}$, respectively, at $4.2 \mathrm{~K}, 10 \mathrm{~T}$ [3]. The 
TABLE I

Phasf Assfmblaghs ObShrved in Quenched Bi-2212/Ag Alloy TaPes Processed under Various $P_{\mathrm{O} 2 .}$. Sampies Were Quenched Every $5{ }^{\circ} \mathrm{C}$ during

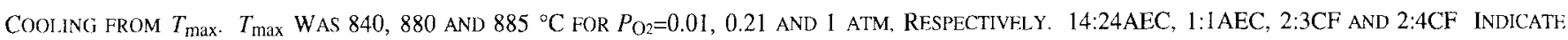
$(\mathrm{Sr}, \mathrm{Ca})_{14} \mathrm{Cu}_{24} \mathrm{O}_{y},(\mathrm{Sr}, \mathrm{Ca}) \mathrm{CuO}_{y}, \mathrm{Bi}_{2}(\mathrm{Sr}, \mathrm{Ca})_{3} \mathrm{O}_{y}$ AND Bi $2(\mathrm{Sr}, \mathrm{Ca})_{4} \mathrm{O}_{y}$, RESPECTIVFL $Y$.

\begin{tabular}{llll}
\hline$T\left({ }^{\circ} \mathrm{C}\right)$ & $P_{\mathrm{O} 2}=0.01 \mathrm{~atm}$ & $P_{\mathrm{O} 2}=0.21 \mathrm{~atm}$ & $P_{\mathrm{O} 2}=\mathrm{I}$ atm \\
\hline 885 & & liquid, 14:24AEC, 2:4CF \\
\hline $880-870$ & & liquid, 1:1 AEC, 2:4CF & liquid, 14:24AEC, 2:4CF \\
\hline $865-860$ & & Bi-2212, 1:1 AEC & liquid, 14:24AEC, 2:4CF \\
\hline $855-845$ & Bi-2212, 1:1 AEC & Bi-2212, 14:24AEC \\
\hline $840-835$ & liquid, 1:1AEC, 2:3CF & Bi-2212, 1:1 AEC & Bi-2212, 14:24AEC \\
\hline 830 & Bi-2212, 1:1AEC, 2:3CF & Bi-2212, 1:1 AEC & Bi-2212, 14:24AEC \\
\hline
\end{tabular}

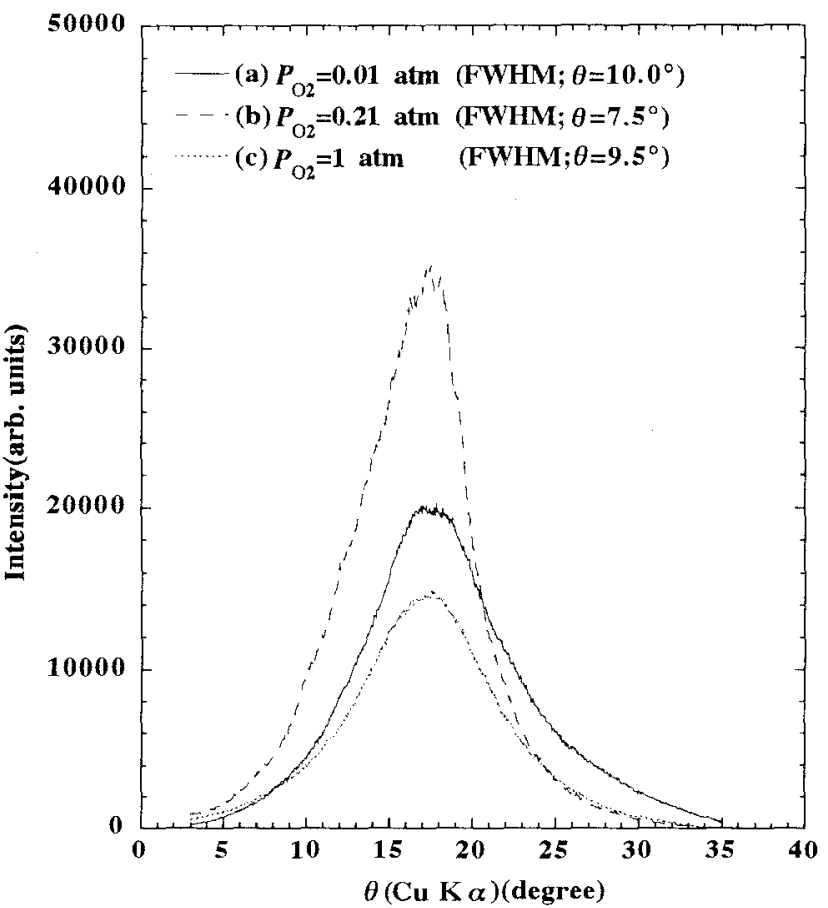

Fig. 3. X-ray rocking curves of 0010 reflection of the Bi-2212/Ag alloy tape fully processed in $P_{\mathrm{O} 2}=$ (a) 0.01 , (b) 0.21 , and (c) $1 \mathrm{~atm}$. The full width at half maximum (FWHM) are $\theta=10.0,7.5$ and 9.5 for $P_{\mathrm{O} 2}=0.01,0.21$ and $1 \mathrm{~atm}$, respectively.

micrographs of the fully processed tape (Fig. 2) suggest that the lowest $J_{\mathrm{C}}$ in $P_{\mathrm{O}_{2}}=0.01 \mathrm{~atm}$ is due to the smallest volume fraction of $\mathrm{Bi}-2212$ in the fully processed tape. However, it is not apparent from the microstructures in Fig. 2 why $J_{\mathrm{c}}$ is higher in tape processed in $P_{\mathrm{O} 2}=1 \mathrm{~atm}$ than in $0.21 \mathrm{~atm}$.

There are several types of grain boundaries in the fully processed $\mathrm{Bi}-2212$ tapes [9],[10]. The most frequently observed (001) twist boundaries were within a colony, while
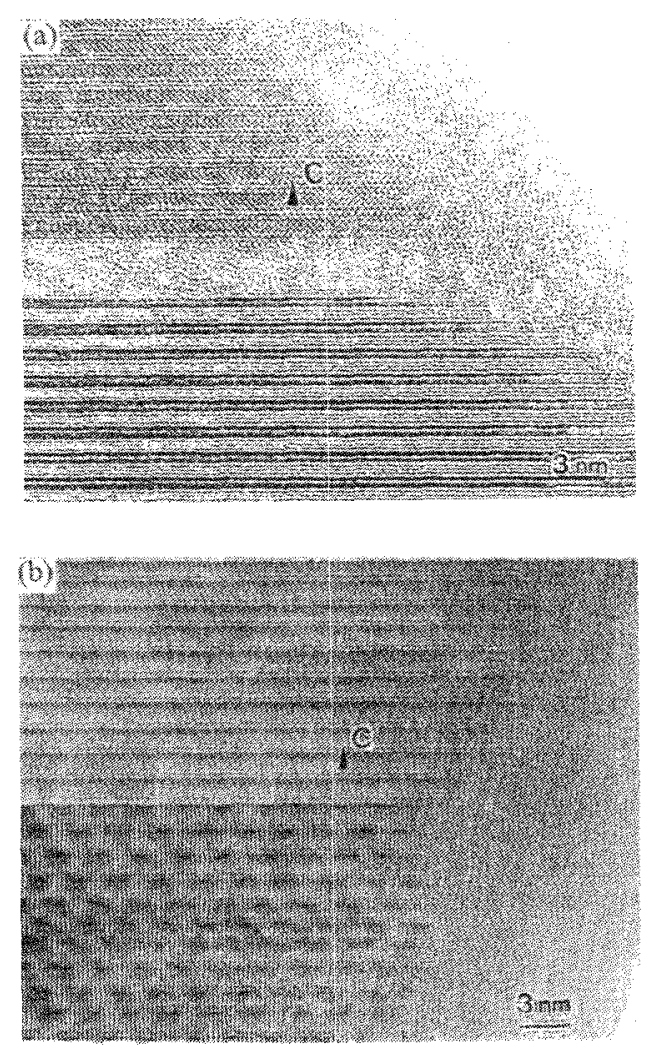

Fig. 4. HR-TEM images of two types of $(00 \mathrm{l})$ twist grain boundaries observed in fully processed B-2212/Ag alloy tapes. (a) Twist boundary with an amorphous layer at the grain boundary. (b) Twist boundary without an amorphous layer at the grain boundary.

the rarely observed other boundaries like tilt boundaries were at the colony interface as in Ag-sheathed $\mathrm{Bi}-2212$ conductors [10]. Fig. 4 shows HR-TEM images of two typical (001) twist boundaries in fully processed $\mathrm{Bi}-2212$ on the Ag alloy. The incident electron beam is normal to $c$-axis. Fig. 4 (a) shows an amorphous region at the boundary that is a few nanometers thick. Fig. 4 (b) shows a clean boundary with no annorphous material at the boundary. Twist boundaries with amorphous 


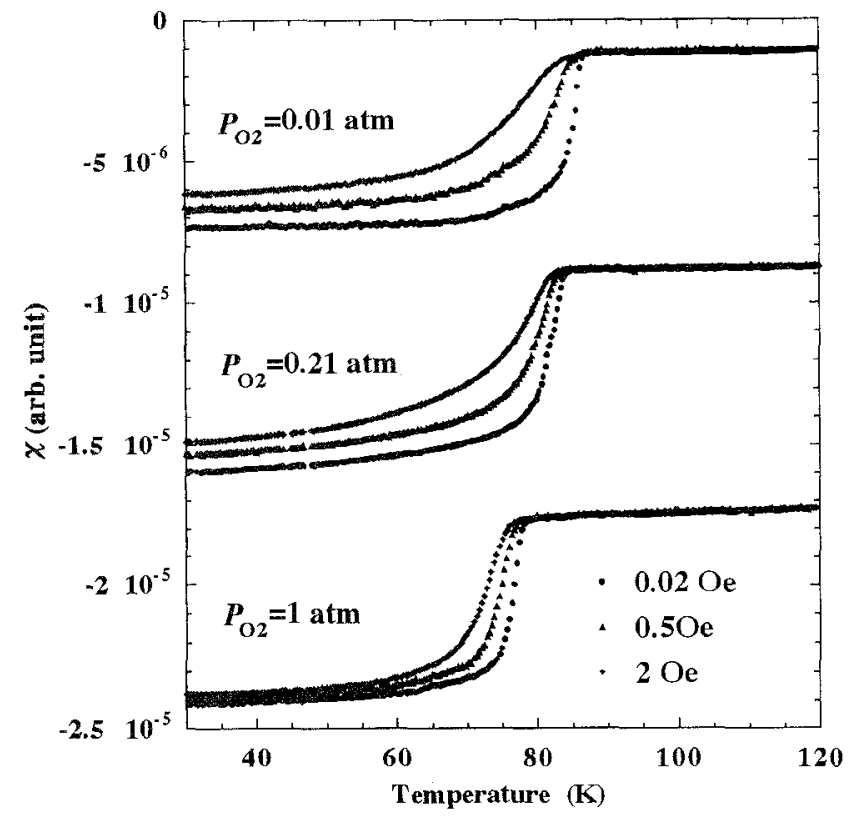

Fig. 5. Temperature-dependence of the real part of AC susceptibility curves of Bi-2212/Ag alloy tapes fully processed in $P_{\mathrm{O}_{2}}=$ (a) 0.01 , (b) 0.21 and (c) $1 \mathrm{~atm}$. The measurements were performed in fields of 0.02 to $2 \mathrm{Oe}$.

layers were frequently observed in tape fully processed in $P_{\mathrm{O}_{2}}=0.01 \mathrm{~atm}$. In tape fully processed in $P_{\mathrm{O}_{2}}=1 \mathrm{~atm}$, most of the twist boundaries did not contain an amorphous layer at the boundary. The population of twist boundaries with the amorphous layer was much lower for tape processed in $P_{\mathrm{O} 2}=1$ atm compared to those in lower $P_{\mathrm{O} 2}$, which was reproducible for a few different specimens prepared from the tapes processed in the same $P_{\mathrm{O} 2}$. These results were independent of the type of substrate.

The real part of AC susceptibility curves for $\mathrm{Bi}-2212 / \mathrm{Ag}$ alloy tapes showed less field-dependence for the tape fully processed in $P_{\mathrm{O}_{2}}=1 \mathrm{~atm}$ compared to $0.01 \mathrm{~atm}$, as shown in Fig. 5. Similar results were obtained for $\mathrm{Bi}-2212 /$ pure $\mathrm{Ag}$ tapes [3]. This indicates the existence of weak grain coupling in tape processed in $P_{\mathrm{O} 2}=0.01 \mathrm{~atm}$ compared to $1 \mathrm{~atm}$. This is in agreement with the "brick wall" model [11], where the amorphous layer, which is assumed to be a normal region, would reduce the supercurrent that could flow in the $c$ direction due to small coherence length of $\mathrm{Bi}-2212$, thus reducing the grain connectivity in the $c$ direction. However, we cannot exclude the "railway switch" model [12], since the HREM observations on small-angle tilt grain boundaries was not enough in this experiment.

The microstructure and $\mathrm{AC}$ susceptibility results suggest that the higher $J_{\mathrm{c}}$ of the tape fully processed in $P_{\mathrm{O} 2}=1$ atm compared to $P_{\mathrm{O} 2}=0.21$ atm is due to improved coupling of $\mathrm{Bi}-2212$ grains in the $P_{\mathrm{O}_{2}}=1$ atm tapes.

\section{CONCLUSION}

The microstructure and phase assemblages of $\mathrm{Bi}-2212 / \mathrm{Ag}$ and Ag alloy tapes depended on both $P_{\mathrm{O}_{2}}$ and heat treatment temperature, but is essentially insensitive to the substrate. The volume fraction of $\mathrm{Bi}-2212$ was larger in tapes fully processed in $P_{\mathrm{O} 2}=0.21$ and $1 \mathrm{~atm}$ than in $P_{\mathrm{O} 2}=0.01 \mathrm{~atm}$, but the volume fraction of $\mathrm{Bi}-2212$ was essentially identical in tapes processed in $P_{\mathrm{O}_{2}}=0.21$ and $1 \mathrm{~atm}$. The tape fully processed in $P_{\mathrm{O}_{2}}=0.21$ atm showed the best grain alignment. Microstructural studies and AC susceptibility measurements suggest that the high $J_{\mathfrak{c}}$ observed for the tape processed in $P_{\mathrm{O}_{2}}=1$ atm is due to improved coupling between the Bi-2212.

\section{ACKNOWLEDGEMENTS}

The authors thank Naomi Inoue-Sugiyama of Hitachi Co. Ltd and Koki Kato of Hitachi Cable Co. Ltd for useful discussions.

\section{REFERENCES}

[1] J. Kase, K. Togano, H. Kumakura, D. R. Dietderich, N. Irisawa, T. Morimoto and $\mathrm{H}$. Maeda, "Partial Melt Growth Process of $\mathrm{Bi}_{2} \mathrm{Sr}_{2} \mathrm{Ca}_{1} \mathrm{Cu}_{2} \mathrm{O}_{x}$ textured tapes on silver," Jpn. J. Appl. Phys., vol. 29, pp. L1096-L1099, 1990.

[2] J. Kase, N. Irisawa, T. Morimoto, K. Togano, H. Kumakura, D. R. Dietderich and $\mathrm{H}$. Maeda, "Improvement in critical current density of $\mathrm{Bi}_{2} \mathrm{Sr}_{2} \mathrm{Ca}_{1} \mathrm{Cu}_{2} \mathrm{O}_{x}$ tapes synthesized by doctor-blade casting and melt growth," Appl. Phys. Lett., vol. 56, pp. 970-972, 1990.

[3] H. Kumakura, H. Kitaguchi, K. Togano and N. Inoue, "Effect of high oxygen partial pressure heat treatment on the superconducting properties of $\mathrm{Bi}_{2} \mathrm{Sr}_{2} \mathrm{Ca}_{1} \mathrm{Cu}_{2} \mathrm{O}_{x} / \mathrm{Ag}$ tapes," J. Appl. Phys., vol. 80, pp. 5162-5168, 1996.

[4] W. Zhang and E. E. Hellstrom, "The effects of oxygen on melt-processing Ag-sheathed $\mathrm{Bi}_{2} \mathrm{Sr}_{2} \mathrm{CaCu}_{2} \mathrm{O}_{8}$ conductors," Supercond. Sci. Technol., vol. 8, pp. $1-9,1995$.

[5] K. Shibutani, T. Hase, S. Hayashi, M. Shimada and R. Ogawa, "Fabrication of Bi-2212-Ag composite solenoid type superconducting magnet," Advances in Superconductivity VII/2, Springer Verlag, Tokyo, pp. 835-838, 1995.

[6] K. Nomura, T. Sasaoka, J. Sato, S. Kuma, H. Kumakura, K. Togano and N. Tomita, "Influence of $\mathrm{Ag}-\mathrm{Au}$ and $\mathrm{Ag}-\mathrm{Cu}$ alloys on $\mathrm{Bi}_{2} \mathrm{Sr}_{2} \mathrm{CaCu}_{2} \mathrm{O}_{x}$ superconductor," Appl. Phys. Lett., vol. 64, pp. 112-114, 1994.

[7] K. Nomura, J. Sato, S. Kuma, H. Kumakura, K. Togano and N. Tomita, "Characteristics of strengthened $\mathrm{Ag}$ substrates for $\mathrm{Bi}_{2} \mathrm{Sr}_{2} \mathrm{CaCu}_{2} \mathrm{O}_{x}$ doctor-blade tapes," Appl. Phys. Lett., vol. 64, pp. 912-914, 1994.

[8] H. Kitaguchi, H. Kumakura, K. Togano, N. Tomita, N. Takeda and N. Igata, "Mechanical and superconducting properties of $\mathrm{Bi}_{2} \mathrm{Sr}_{2} \mathrm{CaCu}_{2} \mathrm{O}_{x} / \mathrm{Ag}-\mathrm{Mg}-\mathrm{Zr}$ alloy composite tapes," Proc. 4th Japan International SAMPE Symposium, Sep. 25 28, 1995, pp. 495-500.

[9] O. Eibl, "Special grain boundaries in high- $\mathrm{T}_{\mathrm{C}} \mathrm{Bi}_{2} \mathrm{Sr}_{2} \mathrm{CaCu}_{2} \mathrm{O}_{8+8}$," Physica C, vol. 168, pp. 239-248, 1990.

[10] Y. Feng, K. E. Hautanen, Y. E. High, D. C. Larbalestier, R. Ray II, E. E Hellstrom and S. E. Babcock, "Microstructural analysis of high critical current density Ag-clad Bi-Sr-Ca-Cu-O (2::2:1:2) tapes," Physica C, vol. 192, pp. 293305, 1992.

[11] L. N. Bulaevskii, J. R. Clem, L. I. Glazman and A. P. Malozemoff, "Model for the low-temperature of Bi-based high-temperature superconducting tapes," Phys. Rev. B, vol. 45, pp. 2545-2548, 1992.

[12] B. Hensel, J.-C. Grivel, A. Jermie, A. Perin, A. Pollini and R. Flükiger, "A model for the critical current in $(\mathrm{Bi}, \mathrm{Pb})_{2} \mathrm{Sr}_{2} \mathrm{Ca}_{2} \mathrm{Cu}_{3} \mathrm{O}_{x}$ silver-sheathed tapes," Physica C, vol. 205, pp. 329-337, 1993. 